\title{
Development of a pre-census database and computer-assisted methodology for conducting the 2021 census in the Republic of North Macedonia
}

\author{
JANE KRSTESKI \\ Advisor on Population and Housing Censuses \\ State Statistical Office, \\ Republic of North Macedonia \\ Email: jane.krsteski@stat.gov.mk
}

The next census in the Republic of North Macedonia is scheduled for 2021; its reference date is set for midnight, 31 March. The census will be conducted using a combined method, with data obtained from several administrative data sources.

A working group was established to identify all state institutions with databases of interest to the census and to visit those institutions to investigate the use of each database. An initial assessment of the data sources was undertaken, according to a set of criteria that evaluated the form, characteristics and manner of updating of the available datasets.

The databases of six institutions were selected, together with the databases of the statistical surveys conducted by the State Statistical Office of the Republic of North Macedonia: 1. Ministry of Interior as the holder of the Citizens Register, 2. Pension and Disability Insurance Fund whose database contains data on all pensioners and employees, 3. Employment Service Agency with a database on both the employed and unemployed (job seekers), 4. Ministry of Labour and Social Policy (having data on social transfers as a source of income), 5. Ministry of Education and Science as the holder of the registers of pupils and students in primary and secondary schools, and 6. Public Revenue Office.

KEYWORDS: Republic of North Macedonia, census, registers

The first censuses within the territory now referred to as the Republic of North Macedonia took place in the 15th century, when Turkish authorities enumerated the tax heads and the male population. Further census data were obtained in the 19th century from Russian, French, Greek, and other sources. The first modern cen-

HungaRian STATISTICAL REVIEW, VOluME 3, NuMBER 1, PP. 46-59. DOI: 10.35618/hsr2020.01.en046 
sus was conducted in 1921, and eight censuses have been taken since World War II. (See the figure.)

Population living in the territory of the Republic of North Macedonia in the census years

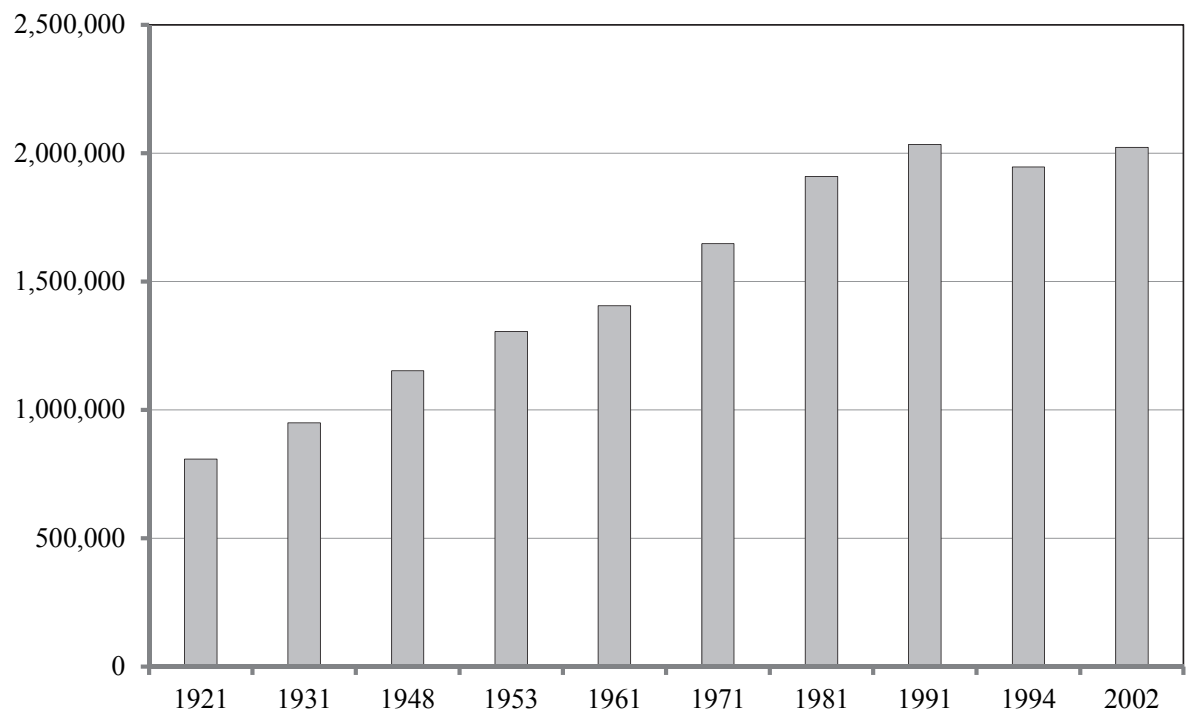

Source: SSO [2019].

The 1991 census was incomplete, so a second was conducted in 1994, which was the first official enumeration of the population in the Republic of North Macedonia since its independence. The most recent census was held in 2002; the one scheduled for 2011 was suspended due to the resignation of all members of the State Census Commission, the political body responsible for the technical implementation of the field census.

In 2007, the SSO (State Statistical Office of the Republic of Macedonia) began to consider the replacement of traditional methods of collecting census data with combined methods. 'Countries with population registers have a strong starting point for the construction of census-like population statistics by augmenting their existing registers with additional survey and linked administrative data sources.' (Shuttleworth-Martin [2016] p. 595.) 'There are clear signs that taking a census is becoming increasingly challenging and costly. The dynamic nature of populations, advances in information technology and demand for more frequent and more detailed statistics are driving changes in methods. This trend can be seen across many developed countries.' (ONS [2012] p. 3.)

Hungarian StatistiCAL ReVIEW, VOluME 3, NUMBER 1, PP. 46-59. DOI: 10.35618/hsr2020.01.en046 
During the preparation of the 2011 census, the SSO considered using prefilled census forms, such as those used in the 2002 census of Slovenia. The method of using administrative registers in the enumeration was applied, for example, in the 1970 census of Finland (Myrskylá [1991]). The basic prerequisite was the existence of a PIN (personal identification number) to identify each person through various administrative registers. The PIN system exists in both Slovenia and Macedonia and is inherited from the former Yugoslavia.

According to the CES (Conference of European Statisticians) recommendations for the 2020 censuses, the main technical and legal conditions for a combined census approach (registers and a full field enumeration) to be practicable are:

' $a$ ) the availability of a population register: this need not necessarily be completely reliable for demographic purposes, but it must be reliable enough to serve as an initial means for determining how many people will be counted and where; and

$b$ ) other administrative registers usable for census purposes: examples include tax lists, social security files, unemployment registers, educational qualification records, and so on.' (United Nations [2015] p. 22.)

However, this concept was not considered feasible at that time, and a decision was made to conduct a traditional census, which was unsuccessful and discontinued on the 11th day of data collection.

The next census is scheduled for 2021, with reference date set for midnight 31 March. The census was originally scheduled for 31 March 2020 but was postponed due to the early parliamentary elections. Preparations for the census began in 2016, and the possibility of using administrative data sources to supply information to prefill partially the census forms was reconsidered.

For that purpose, a working group was created to identify all state institutions with data of interest for the census and to visit those institutions to obtain more detailed information about the content of their registers, classifications used, and dataupdating methods. The initial assessment of the working group was that certain data in the administrative registers could be used.

To decide the most appropriate census method (i.e. either paper questionnaires with pre-printed data, as per the method used by Slovenia in the 2001 census, or an information technology-based methodology), an analysis of the quality of the residential address data in the registers was undertaken. It showed that a significant number of people lived at a different address than their official address of residence, raising an issue for the use of paper forms prefilled with personal information: the inability to locate people at their officially registered address. Moreover, some individuals were found to live outside their enumeration area. This situation would significantly increase the complexity of the fieldwork and the cost of the census. For this reason, a decision was made to conduct the census through the CAPI (computer-assisted personal interviews) method.

HungaRian StaTisticAL REVIEW, VOLUME 3, NUMBER 1, PP. 46-59. DOI: 10.35618/hsr2020.01.en046 
To facilitate the chosen method, the SSO outsourced the development of an online census application, which accesses data from administrative sources in real time for each respondent through their PIN. The SSO also purchased around 5,500 laptops through an international tender.

Meanwhile, the SSO developed a census methodology suitable for the CAPI method and created a PCD (pre-census database) containing information from various institutions, with the main emphasis on those variables that are difficult to collect, such as an individual's occupation, business activity, and education. The methodology for the preparation of the PCD relies on the identification of people by their PIN that links information from several sources to produce a single record for each person. The amount of data for everyone in the PCD varies depending on the extent of their personal information within the various registers. During census fieldwork, the census application can extract data directly from the PCD while the person is being interviewed. The PIN of the enumerated person is entered in the application, and data from the PCD is displayed on the screen. The data can then be confirmed or changed according to the actual situation.

\section{Basic evaluation of the sources}

Based on the working meetings with the relevant ministries and institutions and detailed familiarisation with the content of the registers, the sources were divided into primary and secondary data sources. The first group includes those institutions that are directly responsible for the collection and maintenance of data and the dissemination of certain data to other institutions. The second group is composed of those institutions that receive data from the primary institutions.

Based on these criteria, the institutions are divided as follows. Primary data sources: 1. MoI (Ministry of Interior), 2. Agency for Real Estate Cadastre, 3. Registry Office at the Ministry of Justice, 4. ESA (Employment Service Agency), 5. Health Insurance Fund, 6. Central Registry, 7. PDIF (Pension and Disability Insurance Fund), 8. MLSP (Ministry of Labour and Social Policy), 9. MES (Ministry of Education and Science), 10. PRO (Public Revenue Office), 11. Ministry of Health, 12. Ministry of Foreign Affairs, 13. MISA (Ministry of Information Society and Administration). Secondary data sources: 1. Association of Local Self-Government Units and 2. Ministry of Agriculture, Forestry, and Water Economy.

HungaRian STATISTICAL REVIEW, VOluME 3, NuMBER 1, PP. 46-59. DOI: 10.35618/hsr2020.01.en046 


\section{Assessment of the selected registers}

Through an analysis of the datasets available from the above institutions, an initial assessment was made of each of the data sources according to the following criteria:

1. basic analysis of an individual administrative source

- features of the registered persons,

- suitability of the census data,

- updates,

- methodology used (administrative versus statistical approach),

- classification used (harmonisation and standardisation),

indirectly);

- origin of the data of interest (directly from the person or

2. data accuracy (de facto versus de jure registered status);

3. timeliness

- time required to obtain data,

- time required to process the data in the SSO and include them

in the PCD (the reference date of the data from the source and the reference date of the census);

4. availability (data availability frequency);

5. completeness

- registered population,

- double registration,

- sub-registration,

- incomplete registration of the person (missing certain data);

6. comparability (comparability of the same features in different registers);

7. legal basis for obtaining data.

\section{Selection of administrative registers for the needs of the census}

As a result of the analysis, the databases of six institutions were selected that, when combined and accompanied by statistical survey databases from the SSO, form a suitable statistical population database. The following institutions were accepted: 1. MoI (as the holder of the register of citizens), 2. PDIF whose database covers all

Hungarian STATISTICAL REVIEW, VOLUME 3, NuMBER 1, PP. 46-59. DOI: 10.35618/hsr2020.01.en046 
pensioners and employees, 3. ESA with a database on employees and the unemployed (job seekers), 4. MLSP, 5. MES as the holder of pupil and student registers in primary and secondary schools, and 6 . PRO.

The reasons for selecting each of these sources are outlined below.

1. Purpose of the MoI database. The MoI database is a basic administrative source that contains data on all persons with a PIN, regardless of whether they live in the country or abroad or whether they are alive. The official address, place of birth and citizenship of each person are contained within the database.

2. Purpose of the PDIF database. The PDIF database contains information on those receiving a pension.

3. Purpose of the ESA database. The ESA database is used as a source of data on occupation, activity of the employer, and place of work for all officially employed persons. This database offers the possibility to determine the activity status of each person by combining data from two variables (employed/unemployed and type of employment). However, the reliability of the data is problematic because it depends on the date of the last update. Therefore, the database was evaluated based on data from 2015 onwards, which is expected to be more reliable, according to the experience of SSO methodologists.

4. Purpose of the MLSP database. The MLSP database contains information on persons receiving social benefits.

5. Purpose of the MES database. The MES database contains information on the location and grade of pupils and students attending primary or secondary education in the school year (class, grade) and the field of education for secondary school students.

6. Purpose of the PRO database. This database provides an additional source of information on the activity of a person's employer (to supplement the ESA database). Additionally, it serves as one of the sources for determining the present/absent indicator.

7. Purpose of the SSO database (2000 to 2019). The SSO database refers to both enrolled students and graduates in the tertiary education (ISCED [International Standard Classification of Education] levels 6, 7, 8 , and 9), their field of education, place of study, and the highest degree and field of completed education.

A legal framework was established with these institutions for the use of administrative data sources in the census and to verify the cooperation between the holders of administrative data sources and the SSO.

HungaRian StaTisticAL REVIEW, VOLUME 3, NUMBER 1, PP. 46-59. DOI: 10.35618/hsr2020.01.en046 


\section{Preparation of the pre-census database}

Based on these databases, a PCD was developed by the SSO. The variables in the PCD are listed in Table 1.

Table 1

Variables in the pre-census database

\begin{tabular}{|c|c|c|c|}
\hline Field title & Field description & Data type & Source of data \\
\hline PREZIME & Last name & $\operatorname{varchar}(20)$ & MoI \\
\hline$I M E$ & First name & $\operatorname{varchar}(15)$ & MoI \\
\hline MOMPREZ & Maiden name & $\operatorname{varchar}(20)$ & MoI \\
\hline TATIME & Father's name & $\operatorname{varchar}(15)$ & MoI \\
\hline MAJIME & Mother's name & $\operatorname{varchar}(15)$ & MoI \\
\hline$E M B G$ & PIN & $\operatorname{char}(13)$ & MoI \\
\hline$P O L$ & Gender & $\operatorname{char}(1)$ & MoI \\
\hline STATUS & Status & $\operatorname{char}(1)$ & MoI \\
\hline DRZAVJAN & Citizenship code & $\operatorname{char}(3)$ & MoI \\
\hline BROJN & House number & $\operatorname{char}(4)$ & MoI \\
\hline SIFUL & Street code & $\operatorname{char}(11)$ & MoI \\
\hline NASUL & Settlement code & $\operatorname{char}(6)$ & MoI \\
\hline OPSUL & Municipality code & $\operatorname{char}(4)$ & MoI \\
\hline DRZAVARAG & Country of birth code & $\operatorname{char}(3)$ & MoI \\
\hline DRZAVAZIV & Country of residence code & $\operatorname{char}(3)$ & MoI \\
\hline ZANIMANJEID & Occupation code & $\operatorname{char}(4)$ & ESA \\
\hline DANBR_PODOBVRZNIK & Tax number of the employer & $\operatorname{varchar}(13)$ & PRO \\
\hline IME_UCILISTE & School name & varchar(200) & MES \\
\hline MBNAS_DZS & School settlement code & $\operatorname{char}(6)$ & MES \\
\hline$T I P \_U C I L \_S I F$ & School type & $\operatorname{char}(1)$ & MES \\
\hline NASMES & Faculty settlement code & $\operatorname{char}(6)$ & SSO \\
\hline ISCED3 & ISCED levels 3, 4 (attending) & $\operatorname{char}(4)$ & SSO \\
\hline ISCED5 & $\begin{array}{l}\text { ISCED levels 6, 7, 8, } 9 \text { (attending and } \\
\text { finished) }\end{array}$ & $\operatorname{char}(4)$ & SSO \\
\hline$M B$ & Business entity ID & $\operatorname{char}(7)$ & Business Register (SSO) \\
\hline NAZIV & Business entity name & nvarchar(255) & Business Register (SSO) \\
\hline NACEREV2 & Business entity NACE activity code & $\operatorname{char}(4)$ & Business Register (SSO) \\
\hline$M B N A S$ & Business entity settlement code & $\operatorname{char}(6)$ & Business Register (SSO) \\
\hline SOCTRANS & Social transfer & $\operatorname{char}(1)$ & MLSP \\
\hline
\end{tabular}

Note. Here and in the following table, PIN: personal identification number; ISCED: International Standard Classification of Education; ID: identification; NACE (Nomenclature statistique des activités économiques dans la Communauté européenne): European Classification of Economic Activities; MoI: Ministry of Interior; ESA: Employment Service Agency; PRO: Public Revenue Office; MES: Ministry of Education and Science; SSO: State Statistical Office of the Republic of Macedonia; MLSP: Ministry of Labour and Social Policy; varchar: variable number of characters (the maximum number is in brackets); char: fixed number of characters (the number is in brackets); nvarchar: variable number of Unicode characters (the maximum number is in brackets).

HungaRian STATISTICAL REVIEW, VOLUME 3, NUMBER 1, PP. 46-59. DOI: 10.35618/hsr2020.01.en046 


\section{Testing of the pre-census database}

After the integration of all data from different sources in the PCD, a series of testing was done in order to improve its quality. Testing was taken in two phases. First phase was in-house testing and second phase was field-testing.

\subsection{Preliminary testing at the State Statistical Office}

Initial PCD tests were performed at the SSO to assess the methodological approach of its creation and functionality. As expected, the tests confirmed the suitability of the PCD. The next phase involved field-testing in the 2019 Pilot Census.

\subsection{Testing the quality of the data in the pre-census database during the 2019 Pilot Census}

The methodological approach was tested and the quality and scope of the administrative databases were assessed through a field assessment in the 2019 Pilot Census. The PIN of each person was entered and the data available at the SSO were automatically filled in by the application, and the person could confirm or correct the information.

The results showed that MoI data are of high quality; that is, most PINs matched the data available from this source. Differences arose only where there were changes in the previous 10 days, due to the time required for registration with the $\mathrm{MoI}$ and the time required for the SSO to adjust the details in the PCD. However, it was noted that a significant number of people do not live at the official address noted in the register.

Testing of the data on pupils and students attending primary and secondary schools showed that some of them were not enrolled with the correct PIN in the MES register. A letter has been sent to the MES about this issue, and we are currently working to resolve this problem by installing PIN control.

The quality of ESA data, relating to an individual's employment and the activity of her/his employer, is low for persons who entered employment before 2015 and subsequently changed their occupation, while the data on the employer's activity are of good quality. It was also noted that most employers with an extensive network of business units within the country register their employees at the central business unit; thus, for these employees, it is difficult to obtain accurate data on the place of work.

The data from the MLSP, regarding social transfers in the last 12 months, and the data from the PDIF, regarding the recipients of pensions in the last

HungaRian STATISTICAL REVIEW, VOLUME 3, NUMBER 1, PP. 46-59. DOI: 10.35618/hsr2020.01.en046 
12 months, are both of excellent quality. The SSO data for tertiary students are of satisfactory quality; however, several students use an incorrect PIN.

\subsection{Creating the presence/absence indicator}

Despite its advantages, conducting a combined or register-based census has several disadvantages and risks. These include, for example, that registers and other administrative data sources often adopt different concepts and definitions of population-related variables than those that are generally applied in traditional censuses (UNECE [2018]).

Field testing during the 2019 Pilot Census has shown that data is scarce for those living abroad in most registers (except in the MoI where all citizens are registered), and often where data does exist, a 'passive' status is indicated; that is, the entry in the register is not active, according to the methodology used for registration and updating. Although it was initially planned to use only variables that are of interest for the census and which are part of the PCD, the analysis showed that there is an additional possibility to generate an indicator of presence/absence for each person.

This activity started in February 2020 and consisted of two integral parts. First, with an expert from Slovenia, an analysis of the database was undertaken at the State Statistical Office of the Republic of North Macedonia to determine the data that can be used as 'indicators of life', with the intention of developing a definition for the total population. The second part entailed the modification of the PCD and the web application followed by field-testing through another pilot census. However, at the time of writing, this is incomplete and has been postponed due to COVID-19. At this stage, the quality and scope of another source that became available in the autumn of 2019 should also be tested; namely, the MISA's Administrative Register of Citizens which offers data on the PIN of each citizen's father, mother and spouse (if married).

As a result of the analysis, the need arose to develop a methodological approach for generating a presence/absence indicator for each person. Through this indicator, the total population of Macedonia should be defined. This definition is called the 'axiomatic statistical definition for the total population', which is essentially an approach that accepts data in administrative databases as accurate and, based on that principle, elaborates the methodology for defining the presence or absence of a person in the country. That is, it defines the total population of a certain territory at a certain time (according to international recommendations), fully guaranteeing universality and simultaneity, two of the five characteristics ${ }^{1}$ of a census, which are independent of subjective interpretations.

${ }^{1}$ The five characteristics are: $a$ ) individual enumeration; $b$ ) simultaneity; $c$ ) universality; $d$ ) small-area data; $e$ ) defined periodicity.

HungaRian STATISTICAL REVIEW, VOluME 3, NuMBER 1, PP. 46-59. DOI: 10.35618/hsr2020.01.en046 


\subsection{Methodological approach of the axiomatic statistical definition for the total population}

For each person in the PCD, a new database is created with 28 variables, of which eight are especially important. Each of these eight key variables (except for the year of birth which is ideally contained in each register) is information about the status of the person (record) in the register. The combination of these data generates the presence/absence indicator; that is, whether the person lives in the country. The eight key variables are: 1 . year of birth (from MoI); 2. born abroad (from MoI); 3. mother born abroad (from MoI and MISA); 4. father born abroad (from MoI and MISA); 5. activity status (from ESA); 6. PRO status; 7. pension insurance status (from PDIF); and 8. education status (from MES). The status of the person in the databases is determined through additional data from the registers, as described below.

For the place of birth of a person and her/his parents, there are two statuses: 'in the country' and 'abroad'. In the ESA database, in addition to other factors of interest for the census, there are records for the activity status for each person and the date of the last change in status. For example, persons aged 15 to 67 are divided into two main groups: employed and unemployed. For those employed, there are data on the start date of employment, the basis of employment, employment status, and working hours. If the person is employed and these data are available, the status of this record is 'active employee'. For this person, it can be concluded that the person is present in the country at least in the period from the start date of employment until the moment to which the data refer. However, unemployed individuals are divided into three subgroups:

- 'unemployed active' refers to persons who look for work regu-

larly (every 30 days);

- 'unemployed passive1' refers to persons who look for work less regularly (every 180 days);

- 'unemployed passive2' refers to persons who have not looked for work for more than 180 days.

The PRO database contains data on various revenues, the basis for payment, and the date of payment for persons for the previous 12 months. If a person has received some income from any activity in the country for that month, $s /$ he has an 'active' status.

There are three basic statuses in the PDIF database: 'active', 'pensioner', and 'passive'. For active employees, there are data on paid pension insurance contributions and the date of the last payment. For pensioners, there are data for the last payment. A passive status is given to employees if they lost their job and the payment of pension insurance contributions has ceased; however, one can see the date of the last payment.

Hungarian STATISTICAL REVIEW, VOluME 3, NuMBER 1, PP. 46-59. DOI: 10.35618/hsr2020.01.en046 
The MES database of pupils and students attending primary and secondary schools contains data on the current school year. In the register, pupils and students have only one status, 'enrolled', taken from the start of the school year. There is no information if the student left school after that moment. (For the variables used to determine the presence/absence indicator, see Table 2.)

Variables used to determine the presencelabsence of a person in a country

\begin{tabular}{|c|c|}
\hline Name & Description \\
\hline \multicolumn{2}{|r|}{ of the variable } \\
\hline$I N D$ & Basic indicator showing the availability of data from some source \\
\hline TOTAL & Number of records per indicator \\
\hline$A G E_{-} 1$ & Born between 2005 and 2020 - pre-school and primary school pupils \\
\hline$A G E \_2$ & Born between 2000 and 2004 - secondary school students \\
\hline$A G E \_3$ & Born between 1993 and 1999 - tertiary education students \\
\hline$A G E \_4$ & Born between 1985 and 1992 - youngest working population \\
\hline$A G E \_5$ & Born between 1970 and 1984 - middle-age working population \\
\hline$A G E \_6$ & Born between 1955 and 1969 - older working population \\
\hline$A G E \_7$ & Born between 1935 and 1954 - retired population \\
\hline$A G E \_8$ & Born in or before 1934 - oldest population \\
\hline$B O R N \_A B$ & Born abroad - indicator 1 \\
\hline$M O T \_A B$ & Father of the child born abroad - indicator 2 \\
\hline$F A T \_A B$ & Mother of the child born abroad - indicator 3 \\
\hline UJP & Status from PRO database \\
\hline$U C$ & Status from MES database \\
\hline PIOM & Status from PDIF database \\
\hline$A V R M$ & Status from ESA database \\
\hline$I N D \_Z A N \_0$ & Non-availability of data on occupation \\
\hline$I N D \_Z A N \_1$ & Availability of data on occupation \\
\hline$P E R \_1$ & Last update of ESA database between 2015 and 2019 \\
\hline$P E R \_2$ & Last update of ESA database between 2010 and 2014 \\
\hline PER_3 & Last update of ESA database between 2000 and 2009 \\
\hline PER_4 & Last update of ESA database in 1999 or earlier \\
\hline NR_SOURCES & Number of sources with data on activity status \\
\hline TYPE & Main type of usual resident status \\
\hline SUB TYPE & Sub-type of usual resident status \\
\hline DESCRIPTION & Explanation on sub-type \\
\hline
\end{tabular}

Note. PDIF: Pension and Disability Insurance Fund. 


\section{Results of implementing the methodology}

Based on data on the country of birth of the person and the country of birth of his/her mother and father, the data from the MES, ESA, PDIF, and PRO resulted in 290 possible combinations for the entire population covered in the registers. Each of these 290 combinations belongs to one of the three basic population groups: 1. 'present' (part of the total population); 2. 'absent' (not part of the total population); 3. insufficient data to determine.

Examples of a 'present' status include employees with a place of work in the country, unemployed people who look for work every 30 days, and pupils and students in primary and secondary schools in the country. Examples of an 'absent' status include persons who are born abroad and have a spouse, child, and/or parents that are born abroad or they do not appear in any register apart from the MoI.

Based on the 290 combinations, the data are aggregated for the persons for whom there are data in the PCD. Tables 3 and 4 present the distribution of various population groups by year of birth and activity status.

Table 3

Distribution of various population groups, by year of birth (percentage)

\begin{tabular}{|c|c|c|c|c|c|c|c|c|c|}
\hline \multirow[b]{2}{*}{ Population group } & \multirow[b]{2}{*}{ Total } & \multicolumn{8}{|c|}{ Year of birth } \\
\hline & & $\begin{array}{c}2005- \\
2020\end{array}$ & $\begin{array}{l}2000- \\
2004\end{array}$ & $\begin{array}{c}1993- \\
1999\end{array}$ & $\begin{array}{c}1985- \\
1992\end{array}$ & $\begin{array}{c}1970- \\
1984\end{array}$ & $\begin{array}{c}1955- \\
1969\end{array}$ & $\begin{array}{c}1935- \\
1954\end{array}$ & $\begin{array}{l}\text { in } 1934 \\
\text { or before }\end{array}$ \\
\hline Population present in the country & 100.0 & 8.0 & 3.5 & 6.9 & 13.0 & 25.9 & 24.0 & 17.6 & 1.0 \\
\hline \multicolumn{10}{|l|}{ Of which } \\
\hline the employed & 36.4 & 0.0 & 0.2 & 3.3 & 7.1 & 14.7 & 10.6 & 0.4 & 0.0 \\
\hline the unemployed & 3.2 & 0.0 & 0.1 & 0.7 & 0.4 & 0.6 & 1.2 & 0.1 & 0.0 \\
\hline pupils & 10.8 & 8.0 & 2.8 & 0.0 & 0.0 & 0.0 & 0.0 & 0.0 & 0.0 \\
\hline the retired & 13.9 & 0.0 & 0.0 & 0.0 & 0.0 & 0.0 & 2.3 & 11.0 & 0.5 \\
\hline $\begin{array}{l}\text { those whose activity status is } \\
\text { not determined }\end{array}$ & 35.7 & 0.0 & 0.3 & 2.8 & 5.5 & 10.6 & 10.0 & 6.0 & 0.5 \\
\hline $\begin{array}{l}\text { Population not present in the } \\
\text { country }\end{array}$ & 100.0 & 24.9 & 1.7 & 5.5 & 18.0 & 27.6 & 10.1 & 8.7 & 3.5 \\
\hline with the highest probability & 70.4 & 24.9 & 1.6 & 4.8 & 11.6 & 14.2 & 4.2 & 5.6 & 3.5 \\
\hline with high probability & 22.1 & 0.0 & 0.0 & 0.4 & 5.6 & 11.4 & 3.7 & 0.9 & 0.0 \\
\hline possibly & 7.5 & 0.0 & 0.1 & 0.3 & 0.7 & 2.0 & 2.2 & 2.2 & 0.0 \\
\hline No information from any source & 100.0 & 21.8 & 10.9 & 15.1 & 7.1 & 9.6 & 11.6 & 15.9 & 8.1 \\
\hline Total & 100.0 & 12.6 & 5.3 & 8.9 & 11.8 & 21.8 & 20.0 & 16.6 & 3.0 \\
\hline
\end{tabular}

Note. Here and in the following table, deviations from 100.0 result from rounding. 
Distribution of various population groups, by activity status (percentage)

\begin{tabular}{|c|c|c|c|c|c|c|c|c|c|}
\hline \multirow{2}{*}{ Population group } & \multirow{2}{*}{ Total } & \multicolumn{8}{|c|}{ Year of birth } \\
\hline & & $\begin{array}{c}2005- \\
2020\end{array}$ & $\begin{array}{c}2000- \\
2004\end{array}$ & $\begin{array}{c}1993- \\
1999\end{array}$ & $\begin{array}{c}1985- \\
1992\end{array}$ & $\begin{array}{c}1970- \\
1984\end{array}$ & $\begin{array}{c}1955- \\
1969\end{array}$ & $\begin{array}{c}1935- \\
1954\end{array}$ & $\begin{array}{l}\text { in } 1934 \\
\text { or before }\end{array}$ \\
\hline $\begin{array}{l}\text { Population present in the } \\
\text { country (1) }\end{array}$ & 67.9 & 43.1 & 44.6 & 52.3 & 75.0 & 80.8 & 81.8 & 71.9 & 23.4 \\
\hline Total & & 100.0 & 100.0 & 100.0 & 100.0 & 100.0 & 100.0 & 100.0 & 100.0 \\
\hline \multicolumn{10}{|l|}{ Of which: } \\
\hline the employed & & 0.0 & 7.0 & 48.5 & 54.5 & 56.6 & 44.0 & 2.4 & 1.8 \\
\hline the unemployed & & 0.0 & 4.0 & 10.7 & 3.4 & 2.3 & 5.0 & 0.6 & 0.1 \\
\hline pupils & & 99.9 & 80.4 & 0.1 & 0.0 & 0.0 & 0.0 & 0.0 & 0.0 \\
\hline the retired & & 0.0 & 0.0 & 0.0 & 0.0 & 0.2 & 9.5 & 62.8 & 49.5 \\
\hline $\begin{array}{l}\text { those whose activity } \\
\text { status is not deter- } \\
\text { mined }\end{array}$ & & 0.1 & 8.6 & 40.7 & 42.1 & 41.0 & 41.5 & 34.2 & 48.6 \\
\hline $\begin{array}{l}\text { Population not present in } \\
\text { the country (2) }\end{array}$ & 6.1 & 12.0 & 2.0 & 3.7 & 9.3 & 7.7 & 3.1 & 3.2 & 7.0 \\
\hline Total & & 100.0 & 100.0 & 100.0 & 100.0 & 100.0 & 100.0 & 100.0 & 100.0 \\
\hline $\begin{array}{l}\text { with the highest proba- } \\
\text { bility }\end{array}$ & & 100.0 & 92.6 & 87.4 & 64.6 & 51.4 & 41.3 & 64.5 & 99.4 \\
\hline with high probability & & 0.0 & 0.0 & 6.8 & 31.4 & 41.4 & 37.0 & 10.5 & 0.1 \\
\hline possibly & & 0.0 & 7.4 & 5.8 & 4.0 & 7.1 & 21.7 & 25.0 & 0.5 \\
\hline $\begin{array}{l}\text { No information from any } \\
\text { source (3) }\end{array}$ & 26.0 & 44.9 & 53.5 & 44.0 & 15.7 & 11.4 & 15.1 & 24.9 & 69.5 \\
\hline Total $(1)+(2)+(3)$ & 100.0 & 100.0 & 100.0 & 100.0 & 100.0 & 100.0 & 100.0 & 100.0 & 100.0 \\
\hline
\end{tabular}

\section{Conclusions}

As shown in Tables 4 and 5, 67.9\% of the persons in the PCD are accounted as present in the country, while a small proportion $(6.1 \%)$ are potentially absent. However, for a large group of citizens (26\%) in the PCD there is no information from any source (except from the MoI).

The next pilot census will assess the methodology used for the axiomatic statistical definition for the total population and make a direct comparison of the ab- 
sent/present indicator generated based on this methodology with the factual field situation. A concerted effort will be made prior to the next pilot census to obtain additional data on the characteristics of the group for which there is no information in any register (except the MoI) and to search for additional sources of information to maximise the classification of individuals as either present or absent. It is assumed that this group is not homogenous, but rather consists of several subgroups, and it is likely that some are abroad.

The SSO faces a substantial challenge in creating a socially acceptable methodology for the axiomatic statistical definition for the total population. However, the benefits of using such an approach are significant; this methodology fully complies with the international definition of total population, independent of subjective interpretations, and guarantees universal access to data on every person in the PCD. The SSO is committed to full transparency and promoting access to methodology used for defining the total population of the country for all individuals to maintain the trust of the public and data users.

\section{References}

MYRSKYLÁ, P. [1991]: Census by questionnaire - Census by registers and administrative records: the experience of Finland. Journal of Official Statistics. Vol. 7. No. 4. pp. 457-474.

ONS (Office for National Statistics) [2012]: Beyond 2011: Administrative Data Sources Report: NHS Patient Register. November. https://www.ons.gov.uk/census/ censustransformationprogramme/beyond2011 censustransformationprogramme/ reportsandpublications

Shuttleworth, I. - Martin, D. [2016]: People and places: understanding geographical accuracy in administrative data from the census and healthcare systems. Environment and Planning. Vol. 48 No. 3. pp. 594-610. https://doi.org/10.1177\%2F0308518X15618205

SSO (State Statistical Office of the Republic of North Macedonia) [2019]: Statistical Yearbook of the Republic of North Macedonia. http://www.stat.gov.mk/ Publikacii/SG2019/03-Naselenie-Population.pdf

UNECE (United Nations Economic Commission for Europe) [2018]: Guidelines on the Use of Registers and Administrative Data for Population and Housing Censuses. New York, Geneva.

https://www.unece.org/fileadmin/DAM/stats/publications/2018/ECECESSTAT20184.pdf

United NATIONS [2015]: Conference of European Statisticians, Recommendations for the 2020 Censuses of Population and Housing. New York, Geneva. https://www.unece.org /fileadmin/DAM/stats/publications/2015/ECECES41_EN.pdf 